\title{
Glutamate: A Mini-Review
}

\author{
Daniel Jaffe*, Jennifer Hewit, Kelly Hamilton, Jessica Burkett and Alexander Bedard \\ Department of Physical Education, United States Military Academy, USA
}

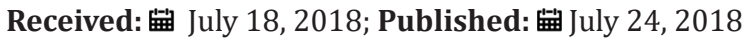

*Corresponding author: Daniel Jaffe, Department of Physical Education, United States Military Academy, West Point, New York, USA.

\section{Mini Review}

As a major excitatory transmitter, glutamate plays an essential role in the functioning of the central nervous system [1]. Glutamate has an immediate impact as an excitatory amino acid and has a role in long-term neuronal potentiation, as a proposed molecular substrate for learning and memory. This neurotransmitter is also known to participate in many metabolic pathways and it plays a pivotal role in the pathophysiology of several neurological diseases-including epilepsy, acute central nervous system trauma, and hepatic encephalopathy [1].

Not only does glutamate play a role in the functioning of the central nervous system, but it is also believed to have an influence on knowledge acquisition and development in humans [2]. Although it is unknown how changes in excitatory or inhibitory neurochemical expression contributes to skill acquisition during development, researchers believe that glutamate possesses a function in the process. Kadosh et al. [2] conducted a study to reveal how differences in cortical glutamate versus gamma-aminobutyric acid (GABA) ratios relate to face proficiency and working memory abilities in children and adults. The researchers revealed that higher glutamate levels in the frontal lobe had a positive correlation with facial processing proficiency in children, but not adults-an effect which was independent of maturation differences in cortical gray matter. Additionally, the researchers discovered that glutamate, GABA levels, and gray matter volume are disconnected at the different stages of human development. The findings of the study confirm that increased excitation during development is associated with neuroplasticity and the achievement of new cognitive skills. The findings also offer a new, approach to examining the connection between cognitive performance and brain development across the human lifespan [2].

Glutamate toxicity occurs due to prolonged elevated concentrations of glutamate around nerve cells. Glutamate sensitivity causes nerve cells to be overstimulated to the point of damage or cell death, where it functions as an excitotoxin [3]. Glutamate causes neurodegeneration by binding to N-methyl-Daspartic acid (NMDA)-receptors and non-NMDA-receptors on nerve cells. By binding to these receptors, glutamate causes positive ions to enter the cell. The entrance of positive ions depolarizes the nerve cell, inducing an action potential to fire. When glutamate is bound to an NMDA receptor, the receptor has the potential to allow large quantities of calcium to enter into the cell once the charge inside the cell rises an adequate amount. In non-NMDA receptors, binding of glutamate allows the entry of positively charged ions other than calcium to enter into the cell [3]. Individuals with Huntington's disease have increased sensitivity of NMDA receptors to glutamate, leading to overstimulation of nerve cells. Alzheimer's patients tend to have damage in glutamatergically-innervated neurons [1].

\section{References}

1. Platt SR (2007) The role of Glutamate in central nervous system health and disease: A review. Veterinary Journal 173(2): 278-286.

2. Kadosh KC, Krause B, King AJ, Near J, Kadosh RC (2015) Linking GABA and glutamate levels to cognitive skill acquisition during development. Human Brain Mapping 36(11): 4334-4345.

3. Hynd M, Scott HL, Dodd PR (2014) Glutamate-mediated Excitotoxicity and Neurodegeneration in Alzheimer's Disease. Neurochemistry International 45(5): 583-595.
ISSN: 2574-1241

DOI: 10.26717/BJSTR.2018.07.001468

Daniel Jaffe. Biomed J Sci \& Tech Res

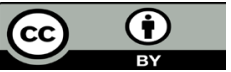

This work is licensed under Creative Commons Attribution 4.0 License

Submission Link: https://biomedres.us/submit-manuscript.php

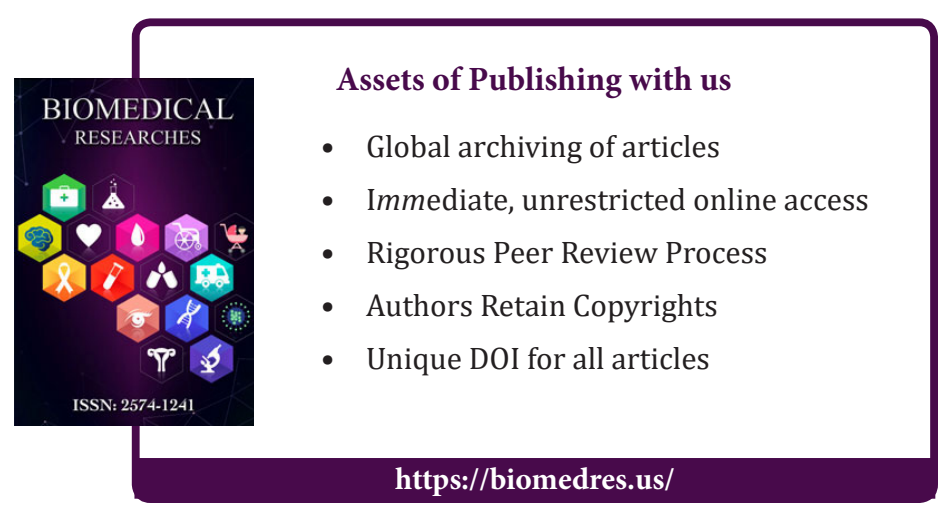

